\title{
Sexualidade das adolescentes em situação de acolhimento: contexto de vulnerabilidade para DST
}

\author{
Sexuality of adolescent girls in foster care: context of vulnerability to STD \\ Sexualidad de las adolescentes en situación de acogida: contexto de vulnerabilidad a enfermedades \\ de transmisión sexual
}

\author{
Lucia Helena Garcia Penna'; Raquel Fonseca Rodrigues ${ }^{I I}$; Liana Viana Ribeiro ${ }^{I I I}$; \\ Mírian Verdeno Paes ${ }^{I V}$; Claudia Rosane Guedes ${ }^{V}$
}

\begin{abstract}
RESUMO: As adolescentes em situação de acolhimento não fogem aos rótulos de adolescente; porém, tendo em vista seu contexto, têm maior vulnerabilidade às doenças sexualmente transmissíveis (DST). Objetivou-se analisar as situações de vulnerabilidade na saúde sexual de adolescentes em situação de acolhimento. É um estudo qualitativo, descritivo-exploratório. Os cenários foram duas unidades de acolhimento do município do Rio de Janeiro. A amostra reuniu 10 adolescentes, entre 13 e 18 anos. Foi utilizada entrevista narrativa, realizada entre junho e setembro de 2014. Aplicou-se a análise temática aos depoimentos. Surgiram duas categorias: A violência no namoro como vulnerabilidade à saúde sexual de adolescentes; e O corpo da adolescente e sua sexualidade: a baixa autoestima como fator de vulnerabilidade. A dificuldade das adolescentes em apontar estratégias de credibilidade e empoderamento retratam um contexto de submissão, subjugação e privação. As adolescentes precisam ser identificadas como sujeitos de direitos e capazes de decidir pela sua própria vida.

Palavras-Chave: Saúde do adolescente; adolescente institucionalizado; vulnerabilidade; saúde sexual.
\end{abstract}

ABSTRACT: Adolescent girls in care are no exception to the labels commonly applied to teenagers, but because of their context are more vulnerable to STDs. This qualitative, descriptive, exploratory study examined situations of vulnerability in the sexual health of adolescents in care. The scenarios were two reception units in Rio de Janeiro city. The sample comprised 10 adolescents from 13 to 18 years old. Data were collected between June and September 2014 using narrative interviews, and treated by thematic analysis. Two categories emerged: violence in dating as vulnerability in adolescents' sexual health; and the teenager's body and her sexuality: low self-esteem as a factor in vulnerability. The girls' difficulty in pointing to strategies for credibility and empowerment portrayed a context of submission, subjugation and deprivation. Adolescent girls need to be identified as subjects of rights and capable of deciding on their own lives.

Keywords: Adolescent health; institutionalized adolescents; vulnerability; sexual health.

RESUMEN: Las adolescentes en situación de acogida no dejan de ser los típicos adolescentes pero, debido al contexto, son más vulnerables a las Enfermedades sexualmente transmisibles (EST). El objetivo fue analizar las situaciones de vulnerabilidad en la salud sexual de adolescentes en situación de acogida. Se trata de un estudio cualitativo, descriptivo y exploratorio. Los escenarios fueran dos unidades de acogida en Río de Janeiro. La muestra reunió a 10 adolescentes con edades entre 13 y 18 años. Se ha utilizado una entrevista narrativa, realizada entre junio y septiembre de 2014. Se utilizó el análisis temático de las declaraciones. Surgieron dos categorías: La violencia en el noviazgo como la vulnerabilidad a la salud sexual de adolescentes; y El cuerpo de la adolescente y su sexualidad: la baja autoestima como factor de vulnerabilidad. La dificultad de las adolescentes en señalar las estrategias de credibilidad y empoderamiento mostró un contexto de sumisión, subyugación y privación. Las adolescentes deben ser identificadas como individuos con derechos y capaces de decidir por su propia vida. Palabras Clave: Salud del adolescente; adolescente institucionalizado; vulnerabilidad; salud sexual.

\section{INTRODUÇÃO}

A adolescência é uma fase da vida na qual ocorrem importantes transformações biológicas, psíquicas e sociais. Nesta etapa, a sexualidade é a manifestação de maior repercussão pessoal, familiar e social. Envolve características biológicas, psicoafetivas, mas também aspectos diretamente influenciados pelos preceitos e valores sociais ${ }^{1}$. Ela é elemento significante na formação da identidade do adolescente, sendo manifestada por diferentes identificações, dentre elas a conduta sexual.

\footnotetext{
IEnfermeira Obstétrica; Doutora em Ciências da Saúde da Criança e da Mulher; Professora Adjunta do Departamento Materno-Infantil e do Programa de Pós-Graduação em Enfermagem da Faculdade de Enfermagem da Universidade do Estado do Rio de Janeiro. E-mail: luciapenna@terra.com.br. IIEnfermeira Obstétrica; Enfermeira da Área da Mulher Ginecologia do Instituto Nacional da Saúde da Mulher, da Criança e do Adolescente Fernandes Figueira. Mestre em Enfermagem (Faculdade de Enfermagem da Universidade do Estado do Rio de Janeiro).E-mail: quelfr@gmail.com.

IIIEnfermeira Obstétrica; Mestre em Enfermagem da Faculdade de Enfermagem da Universidade do Estado do Rio de Janeiro. Brasil.E-mail: liana vian@ hotmail.com.

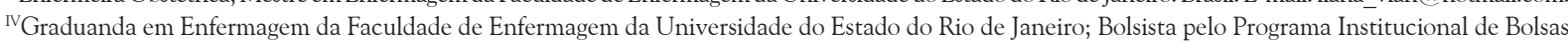
de Iniciação Científica/Conselho Nacional de Desenvolvimento Científico e Tecnológico - Projeto: Vulnerabilidade da saúde reprodutiva e sexual de adolescentes em situação de acolhimento. E-mail: mirian_vrm1993@hotmail.com.

${ }^{v}$ Enfermeira Obstétrica; Professora do Centro Universitário Celso Lisboa; Mestre em Enfermagem da Faculdade de Enfermagem da Universidade do Estado
} do Rio de Janeiro. E-mail: docente.rosane@outlook.com. 
Os principais problemas de saúde dos adolescentes vêm do exercício sexual genital, entre eles, a gravidez não planejada, as complicações da gestação, do parto e do puerpério, a violência sexual, as doenças sexualmente transmissíveis (DST) ${ }^{2}$. No período de 2000 a 2006, foram notificados, oficialmente, 19.793 casos de Síndrome de Imunodeficiência Adquirida (AIDS) no grupo de 13 a 24 anos, correspondendo a $80 \%$ dos casos identificados no Brasil ${ }^{3}$. Em 2009, 41\% das novas infecções pelo Vírus da Imunodeficiência Humana (HIV) ocorreu em pessoas entre 15 e 24 anos de idade. Atualmente, estima-se que 2500 jovens são infectados diariamente com o HIV ${ }^{4}$.

No que diz respeito às adolescentes em situação de acolhimento, elas não fogem dos rótulos comuns a qualquer adolescente. Entretanto, tem acrescido às suas características sociais o contexto de institucionalização que, ao longo da história, segregou e excluiu essa parcela da população. Os adolescentes em acolhimento, devido às situações de desagregação familiar, autoestima baixa, relações sexuais desprotegidas, exposição à violência, comercialização das relações sexuais para sobrevivência, uso de drogas lícitas e ilícitas ficam expostos a inúmeras situações de vulnerabilidade, dentre elas a vulnerabilidade à saúde sexual e reprodutiva ${ }^{5-9}$.

Considerando tal panorama, este estudo teve por objetivo analisar as situações de vulnerabilidade na saúde sexual de adolescentes em situação de acolhimento.

\section{Referencial Teórico-Metodológico}

Estudo qualitativo de caráter descritivo- exploratório que utilizou como referencial teórico-metodológico a narrativa de vida, a qual busca a compreensão do fato ocorrido e tem no relato de vida a marca do narrador ${ }^{10}$.

Foram utilizados, como cenário do estudo, duas unidades de acolhimento do município do Rio de Janeiro que abrigam crianças e adolescentes, um na Zona Norte e outro na Zona Sul da cidade. A amostra foi composta por 10 adolescentes com idade entre 13 e 18 anos. Os critérios de inclusão foram: estar, no período da coleta de dados, institucionalizada nos cenários do estudo; pertencer a qualquer etnia, religião e nível de escolaridade; ter idade entre 12 e 18 anos; autodeclarar a prática de atividades sexuais genitais; estar ou não grávida; ser ou não mãe; e ter a autorização da unidade de acolhimento para participar do estudo. As adolescentes assinaram o Termo de Assentimento, juntamente com os responsáveis pelas unidades de acolhimento (Termo de Consentimento Livre e Esclarecido). A partir da ambientação, iniciou-se a coleta de dados por meio de uma entrevista narrativa, que ocorreu durante os meses de junho a setembro de 2014. As entrevistas foram gravadas e, posteriormente, tran- scritas. $\mathrm{O}$ anonimato foi garantido por meio do uso da letra A, da palavra adolescente, seguido pelo número correspondente à ordem da coleta das entrevistas (de 1 a 10). Utilizou-se, como processo analítico, a análise temática. Esta visa descobrir os núcleos de sentido de uma comunicação cujas frequências signifiquem algo para o objetivo analítico pretendido ${ }^{11}$. Este artigo é um recorte da tese de doutorado intitulada $A$ vulnerabilidade de adolescentes em situação de acolhimento para DST, que faz parte da pesquisa financiada pelo Conselho Nacional de Desenvolvimento Científico e Tecnológico, cujo nome é Saúde reprodutiva e sexual das adolescentes em situação de vulnerabilidade psicossocial.

\section{Resultado e Discussão}

\section{A violência no namoro como vulnerabilidade à saúde sexual de adolescentes}

$\mathrm{Na}$ adolescência, a sexualidade tem um sentido peculiar; para entender as condutas sexuais, é preciso compreender os contextos nos quais eles são produzidos ${ }^{12}$.

As adolescentes que discorreram sobre seus relacionamentos amorosos referiram vivência e prática de agressões físicas e verbais (reciprocidade), porém não identificavam como um problema.

Porque en coloquei a primeira vez esse cabelo, ai men namorado ele trabalhava na boca, ai ele tirou men cabelo todinho numa briga que eu tive com ele. (A2)

Eu fiquei pouco tempo com ele, porque ele voltou a usar droga e começou a me bater. Chutava minha barriga [estava grávida]. (A9)

A violência com e entre os jovens nas relações de namoro tem sido uma realidade apontada. Estudos indicam que 20 a 50\% dos adolescentes já vivenciaram uma situação de violência durante os relacionamentos íntimos ${ }^{13}$.

A reciprocidade da violência entre os jovens nas relações de namoro tem sido apontada, inclusive em outros estudos, os quais detectaram que pelo menos $30 \%$ das meninas agrediam fisicamente os namorados e que $17 \%$ deles também já agrediram suas namoradas ${ }^{14}$. Esses dados sugerem que a agressão é o instrumento de comunicação entre os pares. Os comportamentos de controle são considerados como uma maneira de demonstrar amor, em que o ciúme se apresenta como ingrediente importante numa relação de namoro ${ }^{15,16}$. Com isso, se as normas sociais e culturais nas quais os jovens estão inseridos sustentam a violência, este tipo de comportamento torna-se aceitável para diversas situações.

Cabe destacar que, comumente, as adolescentes em situação de acolhimento apresentam histórico de violência em seu contexto familiar e nas relações interpessoais por elas estabelecidas (violências física, sexual, psicológica e social) ${ }^{17-19}$. É possível pensar a relação entre essas realidades de violência vividas 
anteriormente, influenciando no modo de condução de seus relacionamentos amorosos, como uma continuidade social naturalizada. Essa relação tem sua explicação na noção de aprendizagem social, na qual o comportamento de cada pessoa é determinado pelo ambiente em que está inserido, por meio da observação, reforço, modelagem ou coação ${ }^{20}$. A família ou o local onde vivenciaram sua infância (período de formação da personalidade) é identificado não só como um ambiente que pode viabilizar os comportamentos agressivos, mas também como um espaço que pode levar o indivíduo a interiorizar valores promotores de condutas violentas ${ }^{21}$.

Ele [padrasto] bate nela [na mãe]. Ela parece que ela gosta. Ele ainda bate nela. (A4)

Eles discutiam, mas ele é muito galinha... Assim, o meu padrasto bateu já na minha mãe. Eu vi. [...] Aí ele [padrasto] foi e deu um soco na minha mãe. Aí foi na hora que eu entrei na frente. (A5)

As adolescentes verbalizaram que a maneira por elas encontrada para responder a essas situações é o revide às agressões com outras agressões. Com isto, constrói-se um círculo vicioso e pernicioso, em que essas adolescentes, por não terem outros modelos identificatórios, reproduzem o que aprenderam em casa em seus relacionamentos amorosos ${ }^{22}$.

Aí nós discutia direto. Aí enfiei a faca nele. Ele foi pro hospital, aí ele me bateu. Aí fui e bati nele de volta (A1).

[...] saí correndo pro banheiro e não deixei ele entrar. Na hora que ele conseguiu derrubar a porta, eu comecei a rasgar a perna dele com gilete (A6).

Essas situações - mesmo na condição de ser uma resposta à agressão - não deixam de ser violência, com risco de agravo à integridade dos implicados. A naturalização e banalização da violência nas relações íntimas entre parceiros vêm sendo uma das principais causas de violência contra a mulher. Em sociedades marcadas pelas desigualdades de gênero, a responsabilidade do agressor é banalizada e seu comportamento oportunista, explorador e destrutivo é esquecido. A sociedade, na maioria das vezes, valoriza a imagem da mulher como sendo provocante e culpada. A vergonha que deveria acometer o agressor "é direcionada contra a mulher e a silencia, integrando-a à rede que mantem a dominação ${ }^{23-27}$.

A iniciação, na adolescência, de uma relação afetiva íntima (namoro), para a maioria das adolescentes deste estudo, consiste na idealização de construírem uma família e estabelecerem um lar. Assim sendo, a pressão para estar na relação pode levar as adolescentes a ignorarem e a desculparem a violência a que estão sujeitas. A falta de identificação de uma vida melhor e de uma rede de suporte social contribuem para a normalização da violência e a culpabilização dos atos, tornando difícil o seu reconhecimento e o término dessa relação abusiva ${ }^{24}$.
Embora alguns estudos ${ }^{25,26}$ afirmem que neste tipo de violência (violência no namoro) homens e mulheres são igualmente vítimas e agressores, é preciso, em nossa cultura patriarcal, ampliar o conhecimento quanto às diferenças de gênero. Em sociedades marcadas pelas desigualdades de gênero, a responsabilidade do agressor é banalizada e seu comportamento oportunista, explorador e destrutivo é esquecido. A sociedade, na maioria das vezes, valoriza a imagem da mulher como sendo provocante e culpada.

Eu que implicava com ele. Passava assim, sem ninguém ver, e pisava. Aí, cada um não conseguia ficar sem pena, aí discutia. Ah! Ficava discutindo. (A1)

Ele é bonzinho, é carinhoso. É [...] eu como tinha muito ciúme dele, eu chegava a agredir ele, de chegar a um certo ponto e me agredir também. Mas só nessa parte, fora isso, nunca me bateu não, sem eu agredir ele. (A2)

Geralmente, na violência perpetrada pelo parceiro, a mulher que a vivencia tende a se culpabilizar, convencendo-se de que os seus atos são, única e exclusivamente, os responsáveis pelas reações violentas do parceiro.

Ainda sobre as características dos relacionamentos com os parceiros, as adolescentes afirmaram que eles tinham relações com outras mulheres no período que estavam brigados, muitas vezes, segundo as adolescentes, para causar ciúmes. Nesse caso, a traição passava a ser interpretada como forma de chantagem e, até, de coerção.

Aí nós ficávamos sem nos falar, assim, às vezes. Um dia, dois dias. Aí ele ficava com mulher, ai eu ficava implicando com ele. (A1)

Assim, teve uma vez quando nós terminamos, [...] Ele veio me perguntar só para tentar me colocar ciúme, aí ele me perguntou se... veio me pedir conselho, veio me perguntar se ele ia com a garota ou não ia, que a garota tinha namorado. (A4)

No caso das adolescentes, a separação não era cogitada por inúmeros motivos. Entre eles, o fato de ter nesses relacionamentos, além de vinculações afetivas, interesse social, tanto como status dentro da comunidade ou na instituição de acolhimento por estar com o homem poderoso (traficante ou o adolescente popular), quanto uma opção de ter onde morar, já que as adolescentes que tinham os namorados fora das instituições de acolhimento foram morar com eles, logo no primeiro dia que ficaram.

Outro motivo para a permanência nas relações é que, em função das adolescentes não possuírem um vínculo com a família, viam no parceiro a possibilidade da construção de uma vida diferente e cujos desejos pessoais eram idealizados e os anseios e necessidades poderiam ser preenchidos e correspondidos pelo parceiro. Um terceiro motivo deve-se ao próprio contexto 
de exclusão em que vivem, no qual inúmeras perdas - ou até mesmo ausências - fazem parte de sua história: exclusões de toda ordem - familiar, social, econômica e cultural. A perda do parceiro traz insegurança e medo de mais uma exclusão, porque elas deixam de fazer parte da vida de outra pessoa.

Com isso, nas situações de ameaça da perda do parceiro e dos ganhos com o relacionamento, as adolescentes justificavam seus medos com a desculpa de que seus parceiros queriam lhe causar ciúmes tendo relacionamentos fora do namoro. Essas manifestações de ciúmes, apontadas pelas adolescentes, são valorizadas em nossa sociedade como sinônimo de amor ou de estratégia de investimento na relação ${ }^{28}$.

De fato, este entendimento social, disseminado entre os jovens, tem sustentado o aumento da incidência de contaminação pelo HIV, sobretudo sua feminização ${ }^{29}$. As mulheres ficam mais expostas à contaminação, pois apresentam dificuldade e constrangimento em usar a camisinha ou solicitar seu uso ao parceiro, devido ao medo de perder sua confiança e, consequentemente, vivenciar a separação ou, até mesmo, algum tipo de violência ${ }^{30}$. As mulheres, histórica e culturalmente, vivem em condições maiores de vulnerabilidade em virtude da sua submissão ao parceiro. Os homens tendem a se expor mais por acreditarem numa falsa imunidade, por terem a infidelidade aceita naturalmente pela sociedade e por serem eles os responsáveis pela utilização ou não da camisinha. Em contrapartida, as mulheres tornam-se prejudicadas em iniciar uma conversa com o parceiro em torno de uma prática sexual mais segura e abdicam do uso da camisinha na crença do amor romântico ${ }^{31-33}$.

O corpo da adolescente e sua sexualidade: a baixa autoestima como fator de vulnerabilidade

As adolescentes, ao discursarem sobre a percepção que têm sobre seu corpo, apontaram vergonha de expô-lo ao parceiro ou insatisfação com o corpo que possuem.

Ai eu estou ficando muito gorda. Eu me acho horrível. Me acho gorda. Me acho horrível! (A1)

Eu tenho vergonha ainda de ficar pelada na frente dele, não sei por que, mas eu sinto vergonha de ficar pelada na frente dele. Aí, assim, nas primeiras vezes eu não deixei não, porque eu ficava com vergonha. Aí depois rolou (sexo oral), porque tava escuro, aí eu deixei ele fazer, ele não tava me vendo mesmo. (A6)

Adolescência é caracterizada pelas mudanças físicas, comportamentais, emocionais, sexuais e sociais e é marcada pelo esforço do indivíduo em corresponder satisfatoriamente às expectativas culturais da sociedade em que vive.

Em uma sociedade na qual o corpo desempenha importante valor social, as adolescentes que não se enquadram nos estereótipos exigidos sofrem ou se comportam como naturalmente excluídas. Estudos apontam que essa alta prevalência de insatisfação com a imagem corporal interfere diretamente na autoestima ${ }^{34,35}$.

Com isso, pode-se afirmar que a construção e percepção do corpo pelas adolescentes transcendem as questões privadas, sofre influência dos espaços sociais mediado pelas inter-relações. Os amigos, a instituição de acolhimento e a família - mesmo que desestruturada, assim como as influências culturais contribuem para a construção da identidade do corpo das adolescentes no contexto em que estão inseridas. Acrescido a isso, tem-se a mídia e as redes sociais. $\mathrm{Na}$ sociedade atual, esses veículos de comunicação exercem importante intervenção nas posturas e comportamentos dos adolescentes, inclusive nas adolescentes em situação de acolhimento.

A cultura da magreza, do corpo voluptuoso, das roupas que modelam os corpos acaba ditando a imagem corporal ideal e desejada por estas adolescentes. A cultura com enfoque demasiado na magreza e a mídia como veículo de massificação desse ideal transforma o corpo em um objeto de projeção de desejos para se alcançar o modelo feminino de beleza ${ }^{36}$.

Paralelamente a essas mudanças corporais, ocorrem as mudanças psicoemocionais, ou seja, a busca pela identidade, a tendência de grupos, a vivência singular e a evolução da sexualidade ${ }^{37}$. A sexualidade aqui entendida como a forma que as adolescentes entram em contato com o mundo e como se percebem, utilizando o corpo como instrumento de conexão e comunicação. Com isso, pode-se afirmar que a sexualidade tem tanto a ver com as crenças, ideologias e imaginações desse grupo quanto com o corpo físico ${ }^{38}$.

Assim sendo, o contexto encontrado nas narrativas das adolescentes que participaram do estudo de vergonha, insegurança, medo e baixa autoestima, associado à falta de apoio familiar, ao uso de droga e à vivência de violência aumentam a vulnerabilidade dessas adolescentes às DST, pois o uso de preservativo nas relações sexuais mantém-se inexistente e de difícil negociação e a prevenção e promoção a sua saúde sexual e reprodutiva não são entendidas como importantes e prioritárias.

Ainda no contexto da vivência da sexualidade pelas adolescentes em situação de acolhimento que participaram do estudo, surgiram, na narrativa de uma adolescente, questões referentes à perda da virgindade. Ela referiu sobre o momento certo de ter a primeira relação sexual e como ela irá lidar esse assunto com a filha. A ideia da manutenção da virgindade na narrativa abaixo demonstra uma associação que a adolescente faz da sexualidade ao amor, contrapondo-se ao prazer dos homens. Ela orienta a perda da virgindade numa relação amorosa baseada em sentimentos de respeito e cumplicidade afetiva. 
Os outros falam que tem idade pra perder a virgindade, mas com 10 anos também é muito ... muito cedo. Mas assim, se você amar uma pessoa, você ver que aquele cara é o certo para você perder a virgindade, pode perder. [...] mas com minha filha não quero isso não. Quero que com 20 anos, 30 anos ela perca a virgindade. Que o homem faz sofrer a mulher. Às vezes ela fica com o garoto, perde a virgindade e não era aquele garoto. (A1)

Atualmente, as adolescentes vivenciam sua sexualidade de forma mais liberal; o ficar e a idade para a primeira relação têm sofrido fortes mudanças. Essa liberdade das mulheres em vivenciar a sexualidade ocorreu a partir da revolução sexual e o advento da pílula anticoncepcional proporcionou-lhes a conquista do direito de sentir prazer nas relações sexuais desvinculado à procriação ${ }^{39}$. Contudo, a perda da virgindade ainda é considerada um rito de passagem, no qual a menina passa do mundo infantil para uma condição de mulher, e é vista como um momento especial, não desvencilhado do amor romântico. Diferentemente, o homem, socialmente, é incentivado a iniciar sua vida sexual o mais precocemente possível, independente do interesse ou vínculo com a parceira, mostrando e demarcando sua virilidade ${ }^{40}$. Dessa forma, os valores diferenciados, social, histórica e culturalmente, entre homens e mulheres atribuídos à primeira relação sexual são baseados nas relações de gênero, no qual o modelo tradicional de virgindade ainda não sofreu modificações de igualdade. Mesmo com as conquistas femininas no que diz respeito às práticas sexuais, as motivações continuam respondendo aos papéis socialmente e culturalmente atribuídos às mulheres, que veem no amor, no romance e nos compromissos os propulsores para a primeira relação. Tais práticas evidenciam que o duplo padrão sexual continua vigente, reforçando as assimetrias de poder nas práticas sexuais e nas difíceis negociações quanto aos métodos de proteção às DST.

Por meio das narrativas de vida, algumas adolescentes também apontaram a vivência de relação homoafetiva.

E assim tia [risos]... eu só tinha saído com menino, aqui estou namorando uma garota. E assim tia... [risos] é diferente. Sei lá... é diferente. Mas a gente ainda não teve relação não. (A8)

Assim tia, quando eu tava no outro abrigo eu acabei beijando uma menina. Mas só beijei. Não tive relação não. Eu namorei com ela 1 mês e pouco. (A9)

Como vem sendo abordado, é na adolescência que a sexualidade assume papel de importância na identidade dos adolescentes. Começam a conhecer e experimentar o próprio corpo e o do outro. Começam a ter desejos e atrações sexuais. Por conseguinte, na adolescência, é comum acontecerem aproximações mais intimas entre adolescentes, inclusive com adolescentes do mesmo sexo. Nas narrativas das adolescentes participantes, pôde-se identificar que as relações afetivas estabelecidas com outras meninas foram resultado de uma identificação e uma aproximação por alguém que divide as mesmas histórias de perdas, exclusões, dificuldades e rejeições. A atração física e o envolvimento surgiram do companheirismo, das escutas e conversas estabelecidas, dos afagos de conforto oferecidos umas para com as outras. Nessa presença e compartilhamento de cenários culturais de constante carência, privação e ausência, os grupos de iguais desempenham papel fundamental no encontro das respostas e das descobertas não oferecidas pelos seus núcleos familiares.

As adolescentes tendem a procurar ligações mais íntimas com outras meninas, com as quais ocorrem as trocas de confidências, conversam sobre as perdas e rejeições, compartilham os jogos de sedução, paquera e namoro e é nesse contexto que, muitas vezes, a atração física ocorre ${ }^{41}$.

\section{Conclusão}

As adolescentes em situação de acolhimento narraram condutas culturalmente construídas, nas quais questões de gênero, violência, exclusão social, familiar, econômica e cultural estavam naturalmente diluídas em seus discursos e demonstravam forte interferência na sua visão de mundo e na relação com elas mesmas, com o outro e com a sociedade. A dificuldade de apontar estratégias de credibilidade e empoderamento retrata um contexto de submissão, subjugação e privação. Os cuidados de prevenção e promoção da saúde sexual tornam-se escassos e o diálogo e a negociação pelo uso do preservativo estão ausentes, colocando-as em maior vulnerabilidade para a DST.

Esse contexto desfavorável, acrescido das características dos adolescentes, em geral, em experimentar o novo, desafiar os limites e ter um pensamento de invulnerabilidade e onipotência coloca as adolescentes em situação de acolhimento em constante situação de vulnerabilidade para DST.

Logo, é preciso, nas ações de saúde, identificar e compreender os contextos de vulnerabilidade que as adolescentes em situação de acolhimento estão inseridas. Deve-se considerar, também, essas adolescentes como sujeitos de direitos e capazes de decidir a respeito de sua própria vida. Preocupar-se em somente informar e prescrever o uso de preservativos e as condutas sexuais certas às adolescentes não são medidas suficientes para a vivência de uma sexualidade plena e um sexo seguro.

As políticas de saúde sexual devem ser construídas e orientadas com ênfase na transmissão de informações e na responsabilidade e empoderamento da adolescente, por meio de acolhimento, escuta sensível, assistência e condições para que as decisões sejam realizadas pelas próprias adolescentes empoderadas. 


\section{REFERÊNCIAS}

1.Ministério da Saúde (Br). Coordenação da Saúde da Criança e do Adolescente. Programa Saúde do Adolescente. Bases Programáticas. 2a ed. Brasília (Br): Secretaria Executiva; 1996.

2.Taquette SR. Feminização da AIDS e adolescência. Adolescência \& Saúde 2009; 6(1):33-40.

3.Ministério da Saúde (Br). Boletim Epidemiológico Aids/ DST. 2011; [citado em 10 jul 2014]. Disponível em: http://www.aids.gov.br/sites/default/files/anexos/publicacao/2011/50652/boletim_aids_2011_final_m_pdf_26659.pdf. 4.Unicef. Opportunity in crisis: preventing HIV from early adolescence to young adulthood. Nova Iorque: Unicef; 2011. 5.Borges IK, Medeiros M. Representações sociais de DST/ Aids para adolescentes de uma instituição abrigo com experiência pregressa de vida nas ruas da cidade de Goiânia. DST - J bras Doenças Sex Transm. 2004; 16(4):43-9.

6.Brandão ER, Heilborn, ML. Sexualidade e gravidez na adolescência entre jovens de camadas médias do Rio de Janeiro, Brasil. Cad Saúde Pública. 2006; 22:1421-30.

7.Pereira Junior, VP. Crianças e adolescentes de rua abrigados: uma etnografia. Rev Urutágua. 2006; [citado em 106. Disponível em: http:/www.urutagua.uem.br/006/06paulojr.pdf 8.Carvalho FT, Neiva-Silva L, Ramos MC, Evans J, Koller $\mathrm{SH}$, Piccinini CA, et al. Sexual and drug use risk behaviors among children and youth in street circumstances in Porto Alegre, Brazil. AIDS Behav. 2006; 10(4):57-66.

9.Morais NA, Morais CA, Reis S, Koller SH. Promoção de saúde e adolescência: um exemplo de intervenção com adolescentes em situação de rua. Psicologia \& Sociedade. 2010; 22:507-18.

10.Glat R. Somos iguais a vocês: depoimentos de mulheres com deficiência mental. Rio de Janeiro:7Letras, 2009.

11.Minayo MCS. Pesquisa Social: teoria, método e criatividade. $9^{a}$ ed. Petrópolis (RJ): Vozes; 2010.

12.Gagnon JH. Uma interpretação do desejo. Rio de Janeiro: Garamond; 2006.

13.Sundaram V. Preventing Youth Violence: Rethinking the Role of Gender in Schools. London/New York: Palgrave Pivot; 2014.

14.Minayo MSC, Assis SG, Njaine K. Amor e Violência: um paradoxo das relações de namoro e do 'ficar' entre jovens brasileiros. Rio de Janeiro: Fiocruz; 2011.

15.Caride S, Machado, C. Violencia sexual no namoro: relevância da prevenção. Psicologia. 2008; 21(1):77-104.

16.James WH; West C, Deters KE; Armijo E. Youlth dating violence. Adolescent. 2000; 35(139):455-65.

17.Carinha JI, Penna LHG. Violência vivenciada pels adolescentes em insituição de abrigamento. Texto contexto - enferm. 2012; 21(1):68-76.

19.Penna LHG, Carinhanha JI, Rodrigues RF. Violência vivenciada pelas adolescentes em situação de rua na ótica dos profissionais cuidadores do abrigo. Rev Eletr Enf. 2010; 12:301-7. 20.Gelles RJ. Intimate violence in families. Thousand Oaks: Sage Publications; 1997.

21.Matos M, Machado C, Caridade S, Silva MJ. Prevenção da violência nas relações de namoro: intervenção com jovens em contexto escolar. Psicologia: Teoria e Prática. 2006; 8(1):55-75

22.Seo KT. Manifestações de ciúme e suas consequências, na dinâmica de relacionamento conjugal. [monografia de conclusão de curso]. Garça (SP): Faculdade de Ciências da Saúde; 2006.

23.Zuwick NA. O corpo violado. In: Grossi PK, Werba GC, organizadores. Violência e gênero: coisas que a gente não gostaria de saber. Porto Alegre (RS): EDIPUCRS; 2001.

24.Ismail F, Berman H, Ward-Griffin C. Dating violence and the health of young women: a feminist narrative study. Health Care for Women International. 2007; 28:453-77.

25.Rizzo CJ. Family and peer contexts shape teen perceptions of dating violence. Child and Adolescent Behavior Letter. 2009; 25(7):1-6.

26.Kaura AS, Lohman BJ. Dating violence victimization, relationship satisfaction, mental health problems, and acceptability of violence: a comparison of men and women. Journal of Family Violence. 2007; 22:367-81.

27.Zuwick NA. O corpo violado. In: Grossi PK, Werba GC, organizadores. Violência e gênero: coisas que a gente não gostaria de saber. Porto Alegre (RS): EDIPUCRS; 2001.

28.Almeida T, Lourenço ML. Ciúme romântico: um breve histórico, perspectivas, concepções correlatas e seus desdobramentos para os relacionamentos amorosos. Revista de Psicologia, Fortaleza. 2011; 2(2):18-32.

29.Romero, LR, Dalben, I. Adolescente é tudo igual? Implicações sobre o comportamento sexual, fatores associados e as práticas preventiva. Atos de Pesquisa em Educação. 2014; 9:742-57.

30.Vieira NFC, Paiva TCH, Sherlock MSM. Sexualidade, DST/Aids e adolescência: não quero falar, tenho vergonha. DST - J bras Doenças Sex Transm. 2001; 13(4):46-51.

31.Araújo MAL, Silveira CB. Vivencia de mulheres com diagnóstico de doença sexualmente transmissível - DST. Esc Anna Nery. 2007; 11:479-8.

32.Almeida LCG, Diniz NMF. Sexual violence: revealing women reality. Rev enferm UERJ. 2004; 12:88-94.

33.Gomes NP, Bonfim ANA, Diniz, NMF, Souza, SS, Couto, TM. Percepção dos profissionais da rede de serviços sobre o enfrentamento da violência contra a mulher. Rev enferm UERJ. 2012; 20:173-8.

34.Graup S, Pereira EF, Lopes AS, Araújo VC, Legnani RFS, Borgatto AF. Associação entre a percepção da imagem corporal e indicadores antropométricos de escolares. Rev Bras Educ Fís Esp. 2008; 22:129-38.

35.Vilela JEM, Lamounier JA, Dellaretti Filho MA, Barros Neto JR, Horta GM. Transtornos alimentares em escolares. J Pediatr. 2004; 80(1):49-54.

36. Conti MA, Gambardella AMD, Frutuoso MFP. Insatisfação com a imagem corporal em adolescentes e sua relação com a maturação sexual. Rev. bras. crescimento desenvolv hum. 2005; 15(2): 36-44.

37.Saito MI. Adolescência, sexualidade e educação sexual. Pediatria Moderna. 2001; 27:3-6.

38. Weeks J. O corpo e a sexualidade. In: Louro GL, organizadora. $O$ corpo educado: pedagogias da sexualidade. Belo Horizonte (MG): Autêntica; 2000.

39.Carinhanha JI. Violência vivenciada pelas adolescentes em situação de rua: bases para o cuidado de enfermagem pela cidadania [dissertação de mestrado]. Rio de Janeiro: Universidade do Estado do Rio de Janeiro; 2009.

40.Borges ALV. Relações de gênero e iniciação sexual de mulheres adolescentes. Rev esc enferm USP. 2007; 41:597-604. 41.Brêtas JRS. A mudança corporal na adolescência: a grande metamorfose. Rev Temas Desenv. 2003; 12:1-16. 